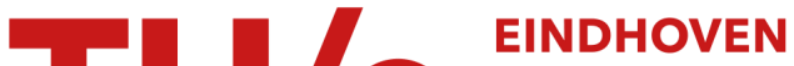 UNIVERSITY OF TECHNOLOGY
}

\section{Control of grid-interfacing inverters with integrated Voltage unbalance correction}

\section{Citation for published version (APA):}

Wang, F., Duarte, J. L., \& Hendrix, M. A. M. (2008). Control of grid-interfacing inverters with integrated Voltage unbalance correction. In IEEE Power Electronics Specialists Conference, 2008 : PESC 2008 ; 15 - 19 June 2008, Capsis Hotel and Convention Center, Rhodes, Greece; proceedings (pp. 310-316). Institute of Electrical and Electronics Engineers. https://doi.org/10.1109/PESC.2008.4591947

DOI:

10.1109/PESC.2008.4591947

Document status and date:

Published: 01/01/2008

\section{Document Version:}

Publisher's PDF, also known as Version of Record (includes final page, issue and volume numbers)

\section{Please check the document version of this publication:}

- A submitted manuscript is the version of the article upon submission and before peer-review. There can be important differences between the submitted version and the official published version of record. People interested in the research are advised to contact the author for the final version of the publication, or visit the $\mathrm{DOI}$ to the publisher's website.

- The final author version and the galley proof are versions of the publication after peer review.

- The final published version features the final layout of the paper including the volume, issue and page numbers.

Link to publication

\section{General rights}

Copyright and moral rights for the publications made accessible in the public portal are retained by the authors and/or other copyright owners and it is a condition of accessing publications that users recognise and abide by the legal requirements associated with these rights.

- Users may download and print one copy of any publication from the public portal for the purpose of private study or research.

- You may not further distribute the material or use it for any profit-making activity or commercial gain

- You may freely distribute the URL identifying the publication in the public portal.

If the publication is distributed under the terms of Article 25fa of the Dutch Copyright Act, indicated by the "Taverne" license above, please follow below link for the End User Agreement:

www.tue.nl/taverne

Take down policy

If you believe that this document breaches copyright please contact us at:

openaccess@tue.nl

providing details and we will investigate your claim. 


\title{
Control of Grid-interfacing Inverters with Integrated Voltage Unbalance Correction
}

\author{
Fei Wang, Jorge L. Duarte, Marcel A. M. Hendrix \\ Department of Electrical Engineering \\ Eindhoven University of Technology \\ 5600 MB Eindhoven, The Netherlands \\ Email: f.wang@tue.nl
}

\begin{abstract}
This paper presents the control of a gridinterfacing inverter with integrated voltage unbalance correction. It is proposed to add an additional function to the inverter to decrease the negative-sequence voltage at the point of connection with the utility grid. Based on a symmetric sequence voltage decomposition and using an improved multi-variable filter, the grid-interfacing inverter intentionally absorbs a small amount of negative-sequence current from the grid, thereby helping to correct the negative-sequence voltage. Although the amplitude reduction contributed by each individual inverter system is small compared to the total negative-sequence component, gridinterfacing inverter modules can collectively achieve substantial results in the grid. The integrated function and proposed control has been verified in simulations and by experiments on a laboratory prototype.
\end{abstract}

\section{INTRODUCTION}

For practical three-phase power systems, problems of voltage unbalance exist. The problems are mainly caused by unbalanced distribution of single-phase and nonlinear loads. Together, these induce unequal voltage drops across transformers and line impedances. These negativesequence voltages are especially troublesome in practical applications, contrary to zero-sequence components which do not exist in three-wire systems. The effects of voltage unbalance are quite severe for electrical machines, power electronic converters, and drives [1].

There are power electronic converters designed for mitigation of voltage unbalance of the utility grid that work by regulating reactive power [2][3], but this approach is not suitable for underground cables where the resistance of a cable dominates its inductance. To maintain a balanced voltage at the load terminals, an often used idea is to inject a series voltage [4][5]. It is straightforward to mitigate the voltage unbalance problem with such converters, but a disadvantage is that they are unused or only lightly loaded when there are no voltage unbalance problems. For dealing with other power quality problems than voltage unbalance, so-called unified power quality conditioners (UPQC) are proposed and continuously improved. However, the UPQC has no energy storage capabilities [6], and should be extended to cope with distributed generation (DG) [7].

Facing the emerging application of distributed generation, power electronics-based grid-interfacing inverters are playing an important role interfacing DGs to the utility grid. In addition to conventional delivery of electricity, ancillary functionality for improvement of power quality problems is being introduced into grid-interfacing inverters [8][9]. In this paper, it is proposed to integrate voltage unbalance correction into the control of grid-interfacing inverters. This does not require more hardware, since the feedback variables for this control are already available. By controlling the negative-sequence currents, which induce opposite negative-sequence voltage drops on the line impedances, the objective of eliminating negativesequence voltages at the point of connection $(\mathrm{PoC})$ with the grid may be achieved.

To investigate the effectiveness of the proposed function, a three-phase four-wire inverter is used to control voltage unbalance correction. The employed inverter operates normally when the utility voltages are balanced, and when unbalanced, performs compensation automatically for negative-sequence voltage, based on utility voltage unbalance factor (VUF) [1]. To this aim, the analysis of negative-sequence current control and a high performance detection for symmetrical sequences are introduced in the following. Then, the inverter control scheme and reference signal generation are presented. Finally, the proposed control methods are verified by simulations, and experimentally tested using a laboratory prototype.

\section{GRID-INTERFACING INVERTER WITH INTEGRATED Voltage Unbalance CORRECTION}

Fig. 1 shows the structure of a three-phase four-wire grid-interfacing system being connected to the utility grid at the POC through LCL filters. It normally synchronizes with the utility grid and delivers electrical energy to the grid from the DC-bus when pre-regulated distributed sources are connected. The voltage unbalance correction function is added, which intentionally regulates negativesequence currents. Note that, in order to obtain a maximum power factor, most grid-interfacing inverters deliver only positive-sequence currents under either balanced or unbalanced conditions. Therefore, the development of this proposed controller differs from the conventional one, and its design will be presented in the next sections of this paper. In view of unbalanced situations, a four-leg inverter topology is used as the circuit to eliminate zero-sequence currents. 


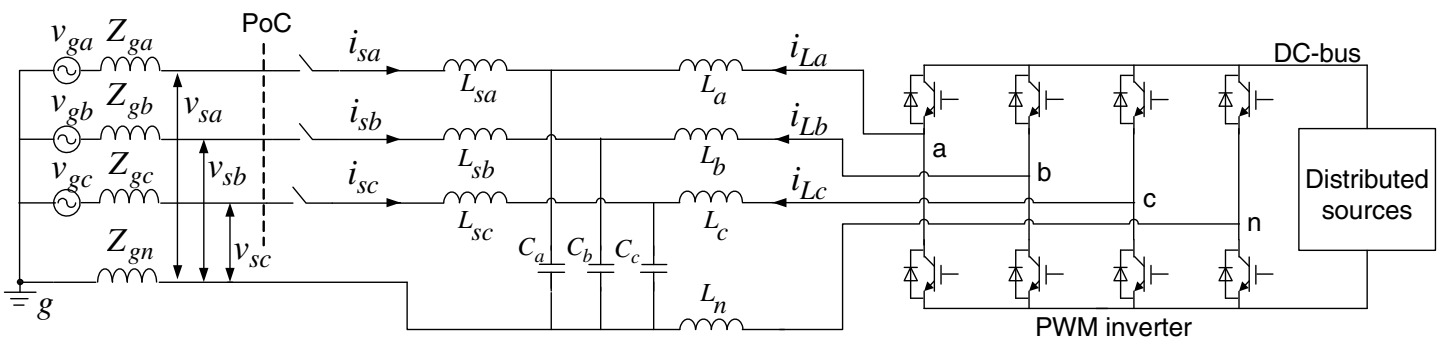

Fig. 1. Three-phase four-wire grid-interfacing inverter at PoC.

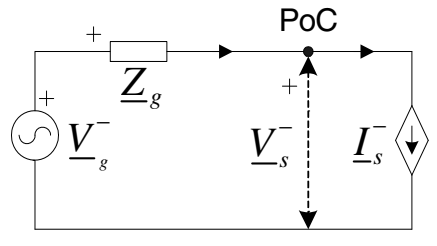

Fig. 2. Negative-sequence equivalent model.

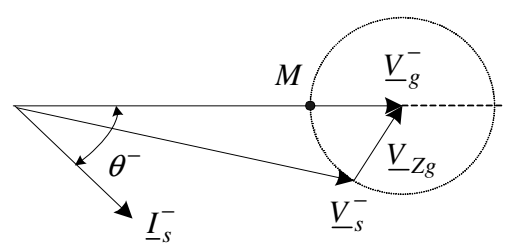

Fig. 3. Phasor diagram of the negative-sequence model.
With the theory of symmetric decomposition for three phase systems [10], unbalanced grid voltages can be divided into three groups, namely positive, negative, and zero sequence voltages. Similarly, current quantities can also be separated. By disregarding the mutual coupling between the grid lines in Fig. 1, an equivalent circuit model for each group of sequence components can be derived [11]. The diagram for negative-sequence components is shown in Fig. 2, where the superscript "." denotes negative sequence. Similarly, the superscript "+" denotes positive sequence. Phasors $\underline{V}_{g}^{-}$and $\underline{V}_{s}^{-}$(in the following, complex numbers are denoted with a bar subscript) are the negative-sequence voltages of the utility grid and at the PoC, respectively. Current $\underline{I}_{s}^{-}$is the negative-sequence current controlled by the grid-interfacing inverter. The equivalent line impedance is represented by $\underline{Z}_{g}$, the equivalent impedance of the utility grid when the line impedances of the three phases are assumed symmetrical.

Accordingly, a phasor diagram showing the change for negative-sequence fundamental current is drawn in Fig. 3. By changing the amplitude and phase of the negativesequence current $\underline{I}_{s}^{-}$, the negative-sequence voltage $\underline{V}_{s}^{-}$ can be regulated through the voltage drops across the line impedance. For a given amplitude $I_{s}^{-}$, the voltage changes along the dashed circle and reaches a minimum value at the point $M$ where $\theta^{-}$(the phase angle between negativesequence voltage and current) equals the negative of impedance angle of $\underline{Z}_{g}$ 's.

Similarly, zero-sequence voltages at the $\mathrm{PoC}$ can be compensated by regulating the zero-sequence currents within the system. This paper only concentrates on the correction of negative-sequence voltages, considering zero-sequence voltages do not exist in case of threewire systems. Of course, zero-sequence voltages can be isolated by transformers when needed. Furthermore, it is noted that measurements of zero-sequence components can be done simply by adding three-phase quantities, while accurate positive- and negative-sequence components are difficult to be determined. Therefore, zerosequence voltage correction can be trivially added to the control based on the proposed control scheme for negative-sequence voltage correction and is not discussed in this paper.

\section{Control Scheme}

\section{A. Determination of Negative-sequence Currents}

Fig. 3 illustrates the basic principle of how to correct unbalanced voltage at the PoC with sequence-current control. It is suggested to determine the negative-sequence currents based on the voltage unbalance factor. To assess unbalanced voltages at the $\mathrm{PoC}$, the voltage unbalance factor, $K_{V U F}$ is defined as the ratio between the amplitude of the negative-sequence voltage $V_{s}^{-}$and the amplitude of the positive-sequence voltage $V_{s}^{+}$. The following constraint equation is proposed to calculate the desired current amplitude $I_{s}^{-}$:

$$
\frac{I_{s}^{-}}{I_{s}^{+}}=\frac{V_{s}^{-}}{V_{s}^{+}}=K_{V U F},
$$

where $I_{s}^{+}$is the amplitude of the positive-sequence current. Then, the resulting $I_{s}^{-}$is derived based on the ratio of unbalance voltages at the PoC from (1).

However, the voltage unbalance factor at the PoC varies with the controlled negative-sequence currents, because the controller utilizes feedforward measurements of $K_{V U F}$ and operates in a open-loop. Consequently, this strategy may cause the value of $K_{V U F}$ in (1) to vary. To ensure a stable correction, a smooth update method for $K_{V U F}$ is added to the control. The flow chart shown in Fig. 4 illustrates how to derive the final $I_{s}^{-}$. The currently measured quantity is referred to as $K_{V U F}(n)$, and the previous one is $K_{V U F}(n-1)$. In Fig. 4 , the minimum threshold $\left(K_{m i n}\right)$ of negative-sequence correction is defined according to practical demands, and 


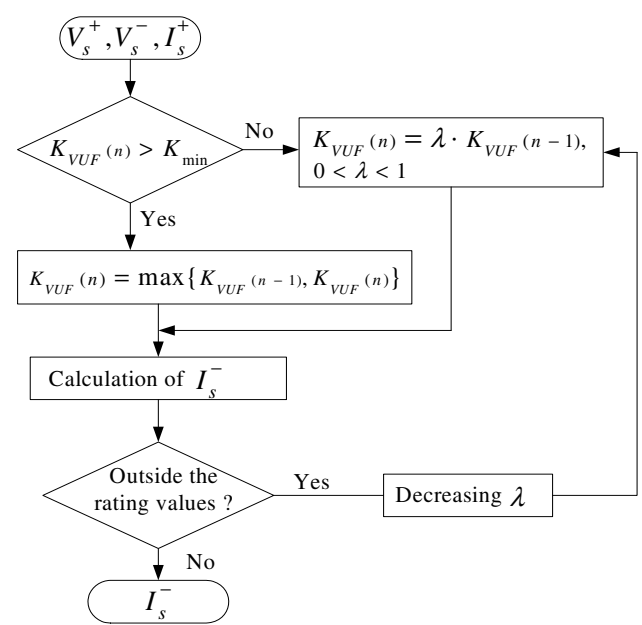

Fig. 4. Flow chart of $K_{V U F}$ determination.

a coefficient denoted by $\lambda$ is introduced for smooth regulation when decreasing the output value of $K_{V U F}$. Note that, for system protection, the current rating of the inverters is always checked before returning $I_{s}^{-}$.

\section{B. Positive- and Negative-Sequence Detection}

The factor $K_{V U F}$ is essential to get the amplitude of negative-sequence currents. Thus the separation of sequence voltages is central to get the value of $K_{V U F}$, as well as to the synchronization with the utility grid. For unbalanced or distorted grid voltages, a multi-variable filter was introduced in [12] for detecting the positive-sequence component in the stationary frame. After modification, this filter is able to directly filter out the fundamental positive and negative-sequence vectors. The following mathematically demonstrates the multi-variable filter for symmetric sequence decomposition.

For unbalanced distorted voltages, the positive- and negative-sequence components are in the $\alpha-\beta$ frame as expressed by

$$
\begin{aligned}
\underline{v}_{\alpha \beta}(t) & =v_{\alpha}(t)+j v_{\beta}(t) \\
& =\sum_{k=1}^{\infty}\left(\underline{V}_{k}^{+} e^{j k \omega_{1} t}+\underline{V}_{k}^{-} e^{-j k \omega_{1} t}\right),
\end{aligned}
$$

where $k$ denotes the harmonic number, $\omega_{1}$ denotes the fundamental radian frequency, and the superscript symbol "o" denotes conjugate.

Let us look for a filter $\underline{G}^{+}(t)$, which can damp all harmonic components of $\underline{v}_{\alpha \beta}(t)$ but the fundamental positive-sequence component in the stationary frame. That is,

$$
\underline{v}_{\alpha \beta}(t) * \underline{G}^{+}(t)=\underline{v}_{\alpha \beta}^{\prime}(t),
$$

where the "** denotes a convolution product, and

$$
\begin{aligned}
\underline{v}_{\alpha \beta}^{\prime}(t)=\underline{V}_{1}^{+} e^{j \omega_{1} t}+ & \sum_{k=3,5 \ldots}^{\infty} \underline{U}_{k}^{+} e^{j k \omega_{1} t} \\
& +\sum_{k=1,3 \cdots}^{\infty} \underline{U}_{k}^{-} e^{-j k \omega_{1} t}
\end{aligned}
$$

with $\left\|\underline{U}_{k}^{+}\right\|<<\left\|\underline{V}_{1}^{+}\right\|$and $\left\|\stackrel{\circ}{\underline{U}_{k}^{-}}\right\|<<\left\|\underline{V}_{1}^{-}\right\|$.

Otherwise stated $\underline{v}_{\alpha \beta}^{\prime}(t) \approx \underline{v}_{\alpha \beta 1}^{+}(t)=\underline{V}_{1}^{+} e^{j \omega_{1} t}$, the fundamental positive-sequence component of $\underline{v}_{\alpha \beta}(t)$ as defined in (2).

By multiplying $\underline{v}_{\alpha \beta}(t)$ and $\underline{v}_{\alpha \beta}^{\prime}(t)$ with $e^{-j \omega_{1} t}$, respectively, which corresponds to a transformation to a positive synchronous rotating frame (PSRF), we obtain from (2) and (3)

$$
\begin{aligned}
& \underline{v}_{\alpha \beta}(t) e^{-j \omega_{1} t}=\underline{V}_{1}^{+}+\sum_{k=2,4 \cdots}^{\infty}\left(\underline{V}_{k}^{+} e^{j k \omega_{1} t}+\underline{V}_{k}^{-} e^{-j k \omega_{1} t}\right), \\
& \underline{v}_{\alpha \beta}^{\prime}(t) e^{-j \omega_{1} t}=\underline{V}_{1}^{+}+\sum_{k=2,4 \cdots}^{\infty}\left(\underline{U}_{k}^{+} e^{j k \omega_{1} t}+\underline{U}_{k}^{-} e^{-j k \omega_{1} t}\right) .
\end{aligned}
$$

It can be seen that the fundamental positive-sequence voltage performs as a DC quantity in the PSRF. Therefore, a simple first order filter $\underline{H}(t)$ with

$$
L[\underline{H}(t)]=\underline{H}(s)=\frac{\omega_{b}}{s+\omega_{b}},
$$

where $\omega_{b}$ is the corner frequency, is sufficient to get $\underline{v}_{\alpha \beta}^{\prime}(t) e^{-j \omega_{1} t}$ from $\underline{v}_{\alpha \beta}(t) e^{-j \omega_{1} t}$ under the conditions of (4). This can be expressed with

$$
\left(\underline{v}_{\alpha \beta}(t) e^{-j \omega_{1} t}\right) * \underline{H}(t)=\underline{v}_{\alpha \beta}^{\prime}(t) e^{-j \omega_{1} t},
$$

or, using Laplace

$$
\underline{v}_{\alpha \beta}\left(s+j \omega_{1}\right) \underline{H}(s)=\underline{v}_{\alpha \beta}^{\prime}\left(s+j \omega_{1}\right) .
$$

Substituting $s \leftarrow s-j \omega_{1}$ into (6) and (8), it follows that

$$
\underline{v}_{\alpha \beta}(s) \cdot \frac{\omega_{b}}{s-j \omega_{1}+\omega_{b}}=\underline{v}_{\alpha \beta}^{\prime}(s) .
$$

From (3), we also have

$$
\underline{v}_{\alpha \beta}(s) \underline{G}^{+}(s)=\underline{v}_{\alpha \beta}^{\prime}(s) .
$$

Therefore, $G^{+}(s)$, the filter we are looking for, in the stationary frame should be equal to

$$
\underline{G}^{+}(s)=\underline{H}\left(s-j \omega_{1}\right)=\frac{\omega_{b}}{s-j \omega_{1}+\omega_{b}} .
$$

By expanding (10) to

$$
v_{\alpha}^{\prime}(s)+j v_{\beta}^{\prime}(s)=\frac{\omega_{b}}{s-j \omega_{1}+\omega_{b}}\left[v_{\alpha}(s)+j v_{\beta}(s)\right],
$$

the following equations are derived

$$
\begin{aligned}
& v_{\alpha}^{\prime}(s)=\frac{1}{s}\left[\omega_{b}\left(v_{\alpha}(s)-v_{\alpha}^{\prime}(s)\right)-\omega_{1} v_{\beta}^{\prime}(s)\right], \\
& v_{\beta}^{\prime}(s)=\frac{1}{s}\left[\omega_{b}\left(v_{\beta}(s)-v_{\beta}^{\prime}(s)\right)+\omega_{1} v_{\alpha}^{\prime}(s)\right] .
\end{aligned}
$$

Similarly, the fundamental negative-sequence component follows as

$$
\underline{v}_{\alpha \beta}(t) * \underline{G}^{-}(t)=\underline{v}_{\alpha \beta}^{\prime \prime}(t),
$$

where

$$
\begin{aligned}
\underline{v}_{\alpha \beta}^{\prime \prime}(t)=\underline{V}_{1}^{-} e^{-j \omega_{1} t}+ & \sum_{k=1,3 \ldots}^{\infty} \underline{U}_{k}^{+} e^{j k \omega_{1} t} \\
& +\sum_{k=3,5 \ldots}^{\infty} \underline{U}_{k}^{-} e^{-j k \omega_{1} t},
\end{aligned}
$$




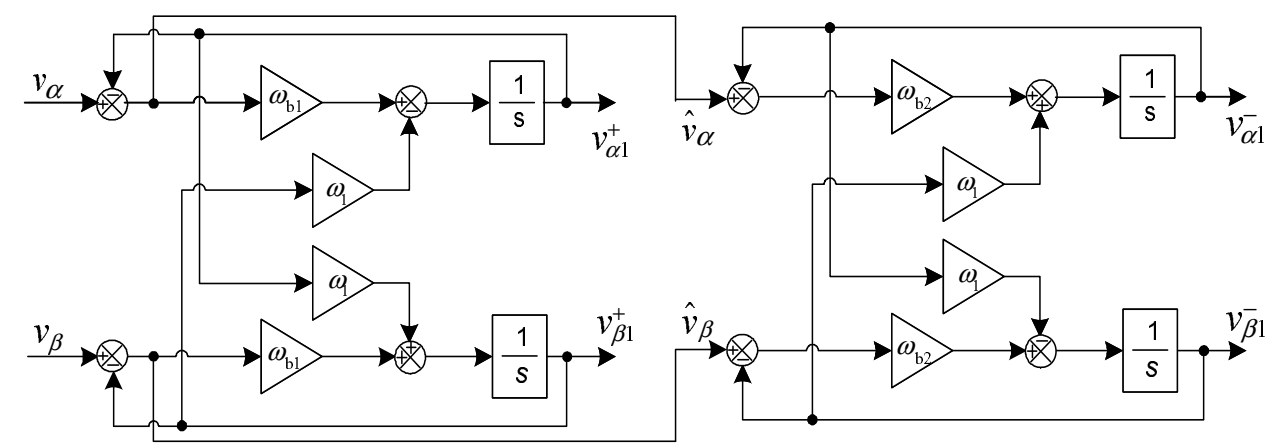

Fig. 5. Implementation diagram of the multi-variable filter.

or $\underline{v}_{\alpha \beta}^{\prime \prime}(t) \approx \underline{v}_{\alpha \beta 1}^{-}(t)$. Similar to (8) and (10), we have

$$
\begin{aligned}
& \underline{v}_{\alpha \beta}\left(s-j \omega_{1}\right) \cdot \underline{H}(s)=\underline{v}_{\alpha \beta}^{\prime \prime}\left(s-j \omega_{1}\right), \\
& \underline{v}_{\alpha \beta}(s) \cdot \underline{G}^{-}(s)=\underline{v}_{\alpha \beta}^{\prime \prime}(s),
\end{aligned}
$$

where

$$
\underline{G}^{-}(s)=\frac{\omega_{b}}{s+j \omega_{1}+\omega_{b}} .
$$

Correspondingly, the equations below are derived:

$$
\begin{aligned}
& v_{\alpha}^{\prime \prime}(s)=\frac{1}{s}\left[\omega_{b}\left(v_{\alpha}(s)-v_{\alpha}^{\prime \prime}(s)\right)+\omega_{1} v_{\beta}^{\prime \prime}(s)\right], \\
& v_{\beta}^{\prime \prime}(s)=\frac{1}{s}\left[\omega_{b}\left(v_{\beta}(s)-v_{\beta}^{\prime \prime}(s)\right)-\omega_{1} v_{\alpha}^{\prime \prime}(s)\right] .
\end{aligned}
$$

Therefore, the detection for $v_{\alpha 1}^{+}(t)+j v_{\beta 1}^{+}(t)$ and $v_{\alpha 1}^{-}(t)-j v_{\beta 1}^{-}(t)$ are approximately achieved from (13) and (17). These equations can be easily implemented in the $\alpha-\beta$ frame by digital control, without complicated transformation to the SRF and the inverse transformation.

In practical applications, the negative-sequence component is too small to be detected accurately. This is because the input signals involve a large proportion of positivesequence components which are difficult to damp totally. Alternative signals $\underline{\widehat{v}}_{\alpha \beta}(t)$, with

$$
\widehat{\widehat{v}}_{\alpha \beta}(t)=\widehat{v}_{\alpha}(t)+j \widehat{v}_{\beta}(t)=\underline{v}_{\alpha \beta}(t)-\underline{v}_{\alpha \beta 1}^{+}(t),
$$

where the dominant positive-sequence component $\underline{v}_{\alpha \beta 1}^{+}(t)=v_{\alpha 1}^{+}(t)+j v_{\beta 1}^{+}(t)$ is abstracted, and can be used as input signals. This will improve the filtering effect for negative-sequence quantities.

Fig. 5 illustrates the implementation diagram of the multiple-variable filter, where the bandwidth $\omega_{b}$ for the positive- and negative-sequence filter is denoted by $\omega_{b 1}$ and $\omega_{b 2}$ respectively (the values can be different and adapted to practical situations). The central frequency $\omega_{1}$ is set at the fundamental frequency of the grid voltage. In case of grid frequency variations the bandwidth can be increased slightly, or $\omega_{1}$ can be adaptively updated with the measured fundamental frequency.

A frequency domain multi-variable filter plot is drawn in Fig. 6, based on (10) and the second equation in (16). Due to unity gain and zero phase-shift of the positive-sequence filter at the central frequency $(50 \mathrm{~Hz})$, $\widehat{v}_{\alpha}(t)+j \widehat{v}_{\beta}(t)$ can be directly derived, see Fig. 5. This manipulation is equivalent to a notch filter at the positive fundamental frequency, as shown in Fig. 6.
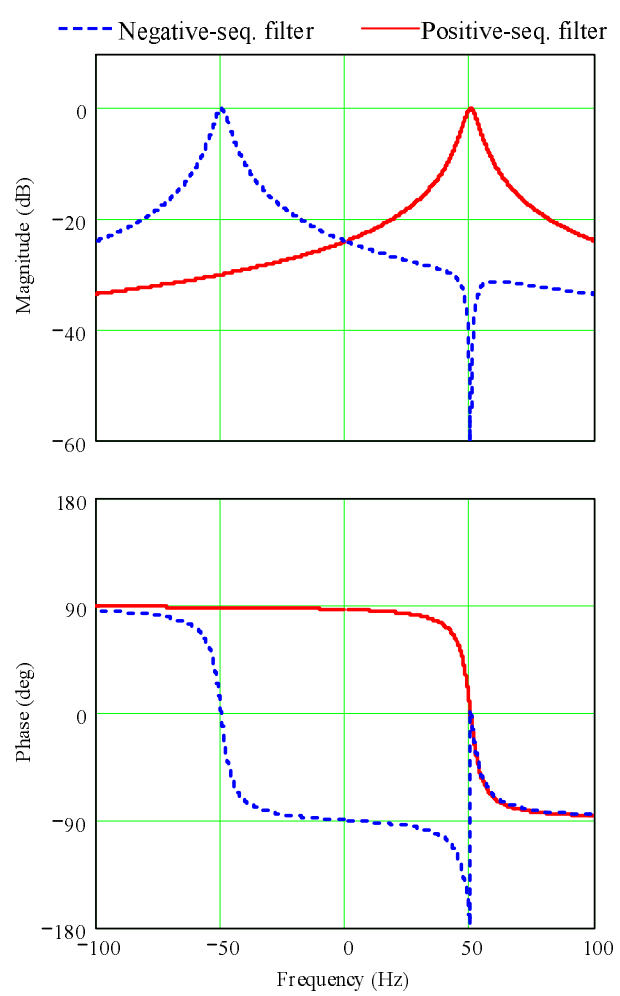

Fig. 6. Multi-variable filter plot in frequency domain with $\omega_{1}=$ $314 \mathrm{rad} / \mathrm{s}$, and $\omega_{b 1}=\omega_{b 2}=20$.

\section{Reference Signals Generation}

Fig. 7 shows the block diagram of the inverter's current reference generator. It consists of the detection of symmetric sequence voltages with a multi-variable filter, the VUF calculation, average power regulation and the signal synthesis. The first two processes have been detailed in the previous two subsections. By utilizing the fundamental positive- and negative-sequence components filtered out by the filter, we can obtain

$$
\begin{aligned}
& V_{m a g}^{+}=\sqrt{{v_{\alpha 1}^{+2}+v_{\beta 1}^{+2}}^{+}} \\
& V_{m a g}^{-}=\sqrt{{v_{\alpha 1}^{-2}+v_{\beta 1}^{-2}}^{-2}}
\end{aligned}
$$

where $V_{m a g}^{+}$and $V_{m a g}^{-}$denote the magnitude of fundamental positive- and negative-sequence voltage, respectively. 


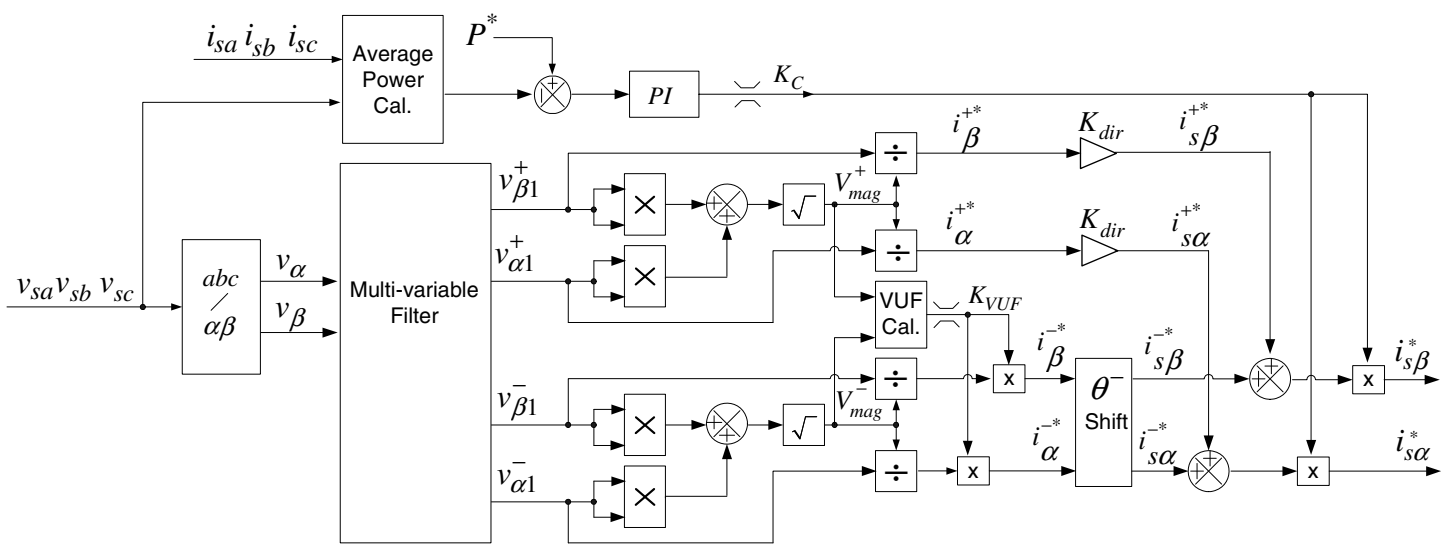

Fig. 7. Current reference generation for the inverter control.

Consequently, two groups of per-unit signals can be derived with divisions, that is $i_{\alpha}^{+*}+j i_{\beta}^{+*}$ and $i_{\alpha}^{-*}+j i_{\beta}^{-*}$, as shown in Fig. 7. According to the principle described in section II, negative-sequence currents are designed to keep a phase-shift $\theta^{-}$with the negative-sequence voltage. This phase-shift equals the negative line impedance angle for the maximum correction effect. Its mathematical derivation is

$$
i_{s \alpha}^{-*}+j i_{s \beta}^{-*}=\left(i_{\alpha}^{-*}+j i_{\beta}^{-*}\right) e^{j \theta^{-}} .
$$

The positive-sequence current references are either inphase or in anti-phase with the positive-sequence component of the grid voltage, depending on the desired direction for energy delivery. In this paper, the gain $K_{d i r}$ is set -1 in order to deliver energy to the utility grid.

In the average power control loop of Fig. 7, the power reference $P^{*}$ is given, which can be determined according to the application, such as the active power generated by upstream DG or the power demanded by the downstream utility grid. In order to eliminate the effects of double fundamental frequency ripple on the measured average power, the parameters should have a small proportional gain and a big integration time constant. In this work, the gain is chosen as 0.04 and the time constant is $0.02 \mathrm{~s}$. The output of the PI controller is used to regulate the amplitudes of the desired currents with the coefficient $K_{c}$.

All together, it follows that the current references $i_{s \alpha}^{*}$ and $i_{s \beta}^{*}$ are derived in the stationary frame. This is beneficial for the controller design, since the controller presented in the next section is also designed in the stationary frame. The mathematical manipulations to optimally implement the above digital process are not the subject of this paper, and will be discussed elsewhere.

\section{Controller for Current Regulation}

Fig. 8 shows the controller structure of the gridinterfacing inverter. It is constructed by a double-loop current controller, that is an outer control loop with proportional-resonant (PR) controllers for eliminating the zero steady-state error of the delivered currents, and an inner capacitor current control loop with simple proportional controllers to improve stability. Instead of direct

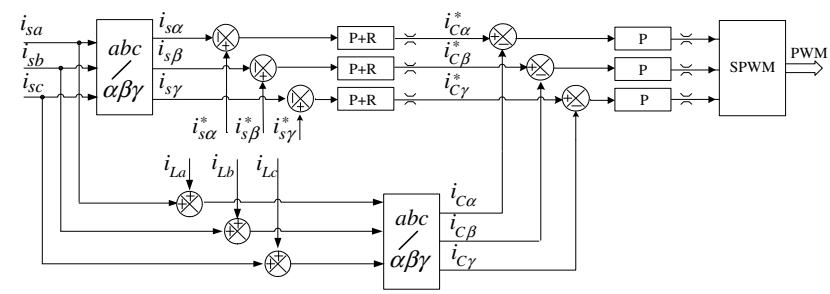

Fig. 8. Structure of the controller for current regulation.

sampling, capacitor currents are calculated from the output currents and the inner filter inductor currents. These currents are measured anyway for over-current protection. To eliminate the zero-sequence currents in unbalanced situations, the current reference $i_{s \gamma}^{*}$ should be zero.

The control for both positive- and negative-sequence components would be much too complicated and computation-time consuming when conventional PI control with coordinate transformation were used. Therefore, it is preferred to choose a PR controller in the stationary frame. A quasi-proportional-resonant controller with high gain at the fundamental frequency is used,

$$
G_{i}(s)=K_{p}+\frac{2 K_{r} \omega_{b r} s}{s^{2}+2 \omega_{b r} s+\omega_{1}^{2}},
$$

where $K_{p}$ is the proportional gain, $K_{r}$ the resonant gain, and $\omega_{b r}$ the equivalent bandwidth of the resonant controller. A detailed design for the PR controller has been presented in [13], it is not duplicated here. Through optimizing, the parameters used in the simulation and experiment are $K_{p}=0.5, K_{r}=50$, and $\omega_{b r}=20$.

\section{Simulation And ExPERIMENTAl RESUlts}

Simulation results from PSIM7.0 are provided to enable the verification of the reference signals generation. System parameters are shown in Table I. In order to easily observe the effects of negative-sequence correction, we intentionally exaggerated the values of the line inductances to the same order as the filter inductors. Therefore, the inductors $L_{s a, b, c}$ are combined with the line impedances, reducing the LCL structure to an LC one. According to the values of the line impedances in Table I, we obtain that $\theta^{-}$equals 


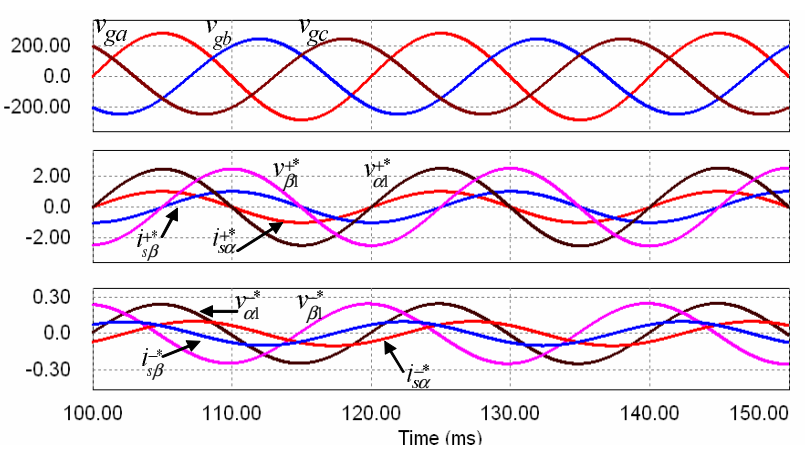

Fig. 9. Simulation results of the reference currents generation. (a) unbalanced grid voltages in a-b-c frame, (b) the per-unit positivesequence currents $i_{s \alpha}^{+*}$ and $i_{s \beta}^{+*}$ in-phase with the positive-sequence voltage, and (c) the negative-sequence current $i_{s \alpha}^{-*}$ and $i_{s \beta}^{-*}$ lags the negative-sequence voltage by $45^{\circ}$ in the $\alpha-\beta$ frame.

$-45^{\circ}$. For a straightforward test of the effectiveness caused by the negative-sequence voltage correction, only fundamental positive- and negative-sequence components are considered in the grid voltages as given in Table I. It should be pointed out that the afore-mentioned control scheme and the multi-variable filter can also be implemented for distorted grid voltages.

To verify the proposed control method with its integrated correction function in a practical set-up, an experiment is carried out with a laboratory prototype that has the same system parameters as the simulation. A 15KVA three-phase programmable AC power source (SPITZENBERGER+SPIES DM 15000/PAS) is used to emulate the unbalanced utility grid. The controller is designed on a dSPACE DS1104 setup by using Matlab Simulink. Due to the long computation time of the controller, a sampling frequency of $8 \mathrm{kHz}$ is used. The switching frequency is twice the sampling frequency.

Fig. 10 (a)-(c) show the experimental waveforms of the grid-interfacing inverter with integrated negative-sequence voltage correction. The plots are the unbalanced grid voltages, the controlled line currents, and the voltages at the PoC, respectively. Using unbalanced grid voltages, the inverter delivers mainly positive-sequence currents to the utility grid and absorbs $10 \%$ of the negative-sequence currents.

The effectiveness of the multi-variable filter in detecting positive- and negative-sequence components from

TABLE I

SYSTEM PARAMETERS

\begin{tabular}{|c|l|l|}
\hline Description & Symbol & Value \\
\hline \multirow{3}{*}{ Grid voltage } & $\frac{V}{g a}$ & $198 \mathrm{~V} \angle 0^{\circ}$ \\
& $\frac{{ }^{\circ}}{g b}$ & $171.71 \mathrm{~V} \angle-125.21^{\circ}$ \\
& $\underline{Z}_{g c}$ & $171.71 \mathrm{~V} \angle 125.21^{\circ}$ \\
\hline Line impedance & $Z_{g a, b, c}$ & $2 \mathrm{mH}, 0.628 \Omega$ \\
\hline Neutral impedance & $Z_{g n}$ & $100 \mathrm{uH}, 0.03 \Omega$ \\
\hline Filter inductor & $L a, b, c$ & $2 \mathrm{mH}, 0.03 \Omega$ \\
\hline Filter inductor & $L_{n}$ & $0.67 \mathrm{mH}, 0.03 \Omega$ \\
\hline Filter capacitor & $C a, b, c$ & $5 \mu \mathrm{F}$ \\
\hline DC-bus & $V_{D C}$ & $700 \mathrm{~V}$ \\
\hline Switching freq. & $f_{s w}$ & $16 \mathrm{kHz}$ \\
\hline
\end{tabular}

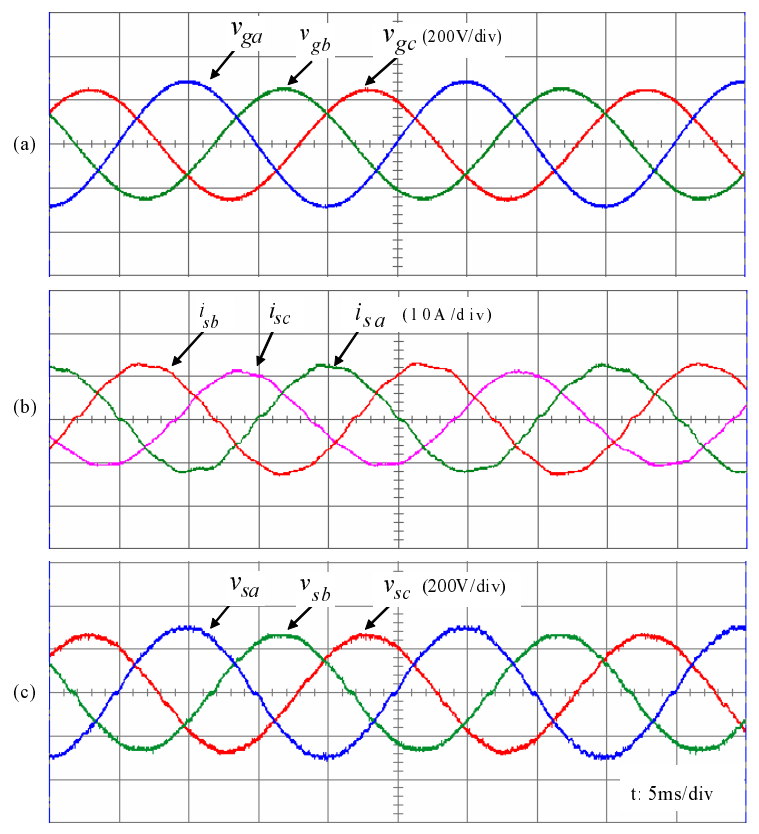

Fig. 10. Experimental results of the grid-interfacing inverter with integrated voltage unbalance correction (a) unbalanced grid voltages, (b) currents delivered by the inverter, and (c) voltages at the PoC.

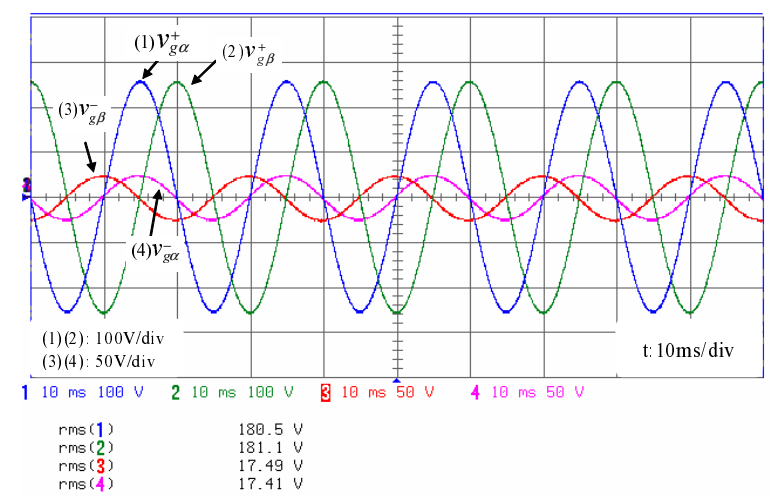

Fig. 11. Experimental waveforms of positive- and negative-sequence voltage detection, where the filtered out fundamental symmetric sequence voltages are derived in the $\alpha-\beta$ frame.

unbalanced voltages is shown in Fig. 11. For observing, these experimental waveforms of the practical controller are reproduced through D/A converters. The RMS value and phase-shift of the positive- and negative-sequence voltages show almost the same results as the calculation results from $a-b-c$ quantities to $\alpha-\beta$ quantities.

To observe the negative-sequence voltage correction, the results are illustrated in the $\alpha-\beta$ frame by decomposing voltages from the $a-b-c$ frame. As seen in Fig. 12 , the amplitude of the negative-sequence voltage at the $\mathrm{PoC}$ is reduced, although the decrease is limited to around $10 \%$. Again note that the line impedance parameters have been exaggerated. In a practical utility grid, for instance $200 \mu \mathrm{H}$ line impedance is more realistic, and then the decrease would be around $1 \%$ for the same conditions. However, based on multiple modules, the effect of the negative-sequence voltage correction will be more pro- 


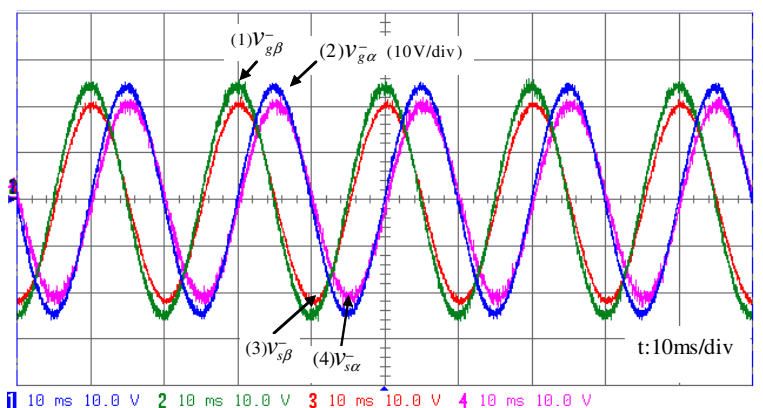

Fig. 12. Experimental results of the negative-sequence voltage correction. The $\alpha, \beta$ components of the negative-sequence voltage of the PoC $v_{s \alpha, \beta}^{-}$show a $10 \%$ amplitude reduction compared with the negativesequence voltage of the grid $v_{g \alpha, \beta}^{-}$.

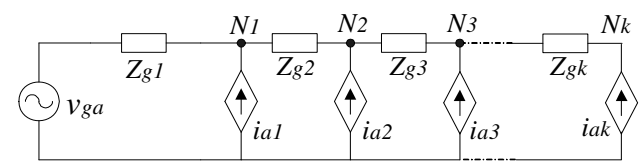

Fig. 13. Per-phase equivalent circuit with multiple modules.

nounced.

For an investigation of multiple modules based on the above described single module, an equivalent circuit is used. Fig. 13 shows the per-phase diagram, where many modules are located in different nodes on a distribution bus and represented by current sources. In order for distributed voltage unbalance correction to succeed, multiple inverter modules on the same PoC of a feeder should show the same control behavior. With the system structure shown, the VUF value may be transfered to each module by an information center where measurements are done centrally. Alternatively, the measurement can be done by the inverters locally.

Qualitatively, we assume that the regulated negativesequence currents by the modules in Fig. 13 can be lumped into a single module, and therefore should behave identical to the single inverter experiment of Fig. 12. Fig. 14 shows the corrected voltage at the $\mathrm{PoC}$ when we simply provide more negative-sequence current. It can be seen that the three-phase voltages tend to be balanced. This generally indicates the effectiveness of distributed voltage unbalance correction. However, it must be noted that the proposed method is only an alternative. It is preferable in an unbalanced situation with small voltage deviation, while the conventional methods are suitable for serious situations with large voltage unbalance.

\section{CONCLUSION}

In this paper, the basic principle and detailed control of grid-interfacing inverters supporting negative-sequence voltage correction has been presented. Based on the voltage unbalance factor and the system's capacity, the inverter absorbs a small amount of negative-sequence current from the grid, thereby correcting the negativesequence voltage. It has been shown that a grid-interfacing

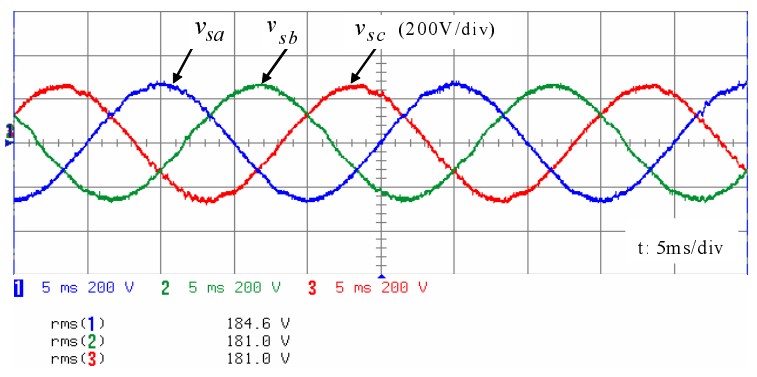

Fig. 14. Experimental waveforms of the negative-sequence voltage correction. The resulting corrected voltages tend to be balanced.

inverter, in addition to its normal operation, can help decrease the negative-sequence voltage at the PoC. By using many of these modules, a substantial improvement is possible. Furthermore, the improved multi-variable filter can filter out positive- and negative-sequence components accurately in case of unbalanced/distorted situations in the stationary frame. The functionality and control scheme are verified by simulation and experimental results of a prototype were given.

\section{REFERENCES}

[1] Annette von Jouanne and Basudeb (Ben) Banerjee, "Assessment of voltage unbalance," IEEE Trans. Power Del., vol. 16, no. 4, pp. 782-790, Oct. 2001.

[2] Hideaki Fujita, and H. Akagi,"Voltage-regulation performance of a shunt active filter intended for installation on a power distribution system,'IEEE Trans. Power Electron., vol 22, no. 3, pp. 1046-1053, May 2007.

[3] Kuang Li, Jinjun Liu, and Zhaoan Wang, and Biao Wei,"Strategies and operating point optimization of STATCOM control for voltage unbalance mitigation in three-phase three-wire systems,"IEEE Trans. Power Del., vol. 22, no. 1, pp. 413-422, Jan. 2007.

[4] Kalyan K. Sen, "SSSC-static synchronous series compensator theory, modeling, and application," IEEE Trans. Power Del., vol. 13, no. 1, pp. 241-246, Jan. 1998.

[5] Vijay B. Bhavaraju and Prasad N. Enjeti, "An active line conditioner to balance voltages in a three-phase system,'IEEE Trans. Ind. Applicat., vol. 32, no. 2, pp. 287-292, Mar./Apr. 1996.

[6] Hideaki Fujita, H. Akagi, "The unified power quality conditioner: the integration of series- and shunt-active filters," IEEE Trans. Power Electron., vol.13, no. 2, pp. 315-322, Mar. 1998.

[7] Dusan Graovac, V. A. Katic, and A. Rufer, "Power quality problems compensation with universal power quality conditioning system," IEEE Trans. Power Del. , vol. 22, no. 2, pp. 968-976, Apr. 2007.

[8] Koen J. P. Macken, Koen Vanthournout, Jeroen Van den Keybus, Geert Deconinck, and Ronnie J. M. Belmans, "Distributed Control of Renewable Generation Units With Integrated Active Filter," IEEE Trans. Power Electron., vol. 19, no. 5, pp. 1353-1360, Sep. 2004.

[9] G. Jos, B.-T. Ooi, D. McGillis, F. D. Galiana and R. Marceau, "The potential of distributed generation to provide ancillary services," in Proc. IEEE Power Eng. Soc. Summer Meeting, Seattle, WA, July, 2000.

[10] P. M. Andersson, Analysis of faulted power systems, New York: IEEE Press, 1995.

[11] Fei Wang, Jorge L. Duate, Marcel A. M. Hendrix, "Weighting function integrated in grid-interfacing converters for unbalanced voltage correction," in Proc. International Conf. on Renewable Energy and Power Quality (ICREPQ), Santander, Spain, 2008.

[12] M. C. Benhabib and S. Saadate, "A new robust experimentally validated phase locked loop for power electronic control," European Power Electronics and Drives Journal, vol. 15, no. 3, pp. 36-48, Aug. 2005.

[13] R. Teodorescu, F. Blaabjerg, M. Liserre and P.C. Loh, "Proportional-resonant controllers and filters for grid-connected voltage-source converters," IEE Proc.-Electr. Power Appl., Vol. 153, No. 5, pp. 750-762, September 2006. 